\title{
Dimensionality and Reliability of the Civilian Mississippi Scale for PTSD in a Postearthquake Community
}

\author{
Moira Inkelas, ${ }^{1}$ Laurie A. Loux, ${ }^{2}$ Linda B. Bourque, ${ }^{3,5}$ Mel Widawski, ${ }^{4}$ \\ and Loc H. Nguyen ${ }^{3}$
}

\begin{abstract}
This study examines psychometric properties of the Civilian Mississippi Scale for posttraumatic stress disorder when administered in a community survey of 656 persons following the 1989 Loma Prieta earthquake. Internal consistency was lower (Cronbach's $\alpha=.73$ ) than for previous analyses of civilian and combat versions of the Mississippi Scale. The analysis produced one strong factor composed of 25 items with regular wording and a second, weaker factor composed of 10 items with reversed wording. Internal consistency was higher when the 10 reversed items were removed (Cronbach's $\alpha=.86$ ); the two factors were negatively correlated. Traumatic experiences and psychological distress measures explained more variance in the 25-item factor than in the 35-item scale. Further studies should focus on content analysis and performance of the reversed items.
\end{abstract}

KEY WORDS: PTSD; Mississippi Scale; disaster; community survey; reliability; validity; assessment.

The Mississippi Scale for Combat-Related Posttraumatic Stress Disorder (Keane, Wolfe, \& Taylor, 1987) has been shown to be a reliable, valid, and easily administered screening measure for PTSD among military veterans, particularly those who saw conflict during the Vietnam War (Kulka et al., 1990, 1991; McFall, Smith, Mackay, \& Tarver, 1990). The Mississippi Scale has been adapted for use

${ }^{1}$ RAND Corporation, Santa Monica, California.

${ }^{2}$ University of Michigan, Ann Arbor, Michigan.

${ }^{3}$ Center for Public Health and Disaster Relief and Department of Community Health Sciences, School of Public Health, University of California, Los Angeles, California.

${ }^{4}$ Office of Academic Computing, University of California, Los Angeles, California.

${ }^{5}$ To whom correspondence should be addressed at Center for Public Health and Disaster Relief and Department of Community Health Sciences, School of Public Health, University of California, Box 951772, Los Angeles, California 90095-1772. Fax: (310) 794-1805. 
with civilian populations by changing the referent from military experiences to "events in the past," dropping the referent in 11 of the items (Vreven, Gudanowski, King, \& King, 1995, p. 94), and adding 4 new items to create a 39-item scale.

Most studies that examine the psychometric properties of the Civilian Mississippi Scale (Lauterbach, Vrana, King, \& King, 1997; Norris \& Perilla, 1996; Vreven et al., 1995) have utilized select populations (e.g., substance abusers, community-based civilians matched to combat veterans) or convenience samples rather than population-based community samples. Internal consistency of the Civilian Version of the Mississippi Scale for Posttraumatic Stress Disorder (C-Mississippi Scale) was high when administered to 668 nonveteran civilians matched to Vietnam veterans on gender, age, ethnicity, and occupation as part of the National Vietnam Veterans Readjustment Study (NVVRS; Kulka et al., 1990; Vreven et al., 1995). However, the internal consistency (.86) and the item-total correlations (mean, .39; range, .10 to .53) were lower than in the combat version (Keane, Caddell, \& Taylor, 1988; Kulka et al., 1990; McFall et al., 1990; Vreven et al., 1995).

Norris and Perilla (1996) examined the reliability of a revised C-Mississippi Scale with 30 items (including 28 of the 39 Civilian Scale items and 2 new items) with simplified 5-point response options that were identical across items. In reliability tests on a convenience sample, Cronbach's $\alpha$ for this Revised Civilian Mississippi Scale was .86 for an English version and .88 for a Spanish version. Persons who reported greater hurricane exposure (Norris \& Kaniasty, 1992) had significantly higher scores than other respondents, but the authors did not report the relationship between the C-Mississippi Scale and the Traumatic Stress Schedule (Norris, 1990).

Lauterbach et al. (1997) examined the psychometric characteristics of the C-Mississippi Scale in two studies that assess trauma exposure and symptom development among undergraduates. Both the 35-item and the 39-item C-Mississippi Scale were examined. Item-total correlations and Cronbach's $\alpha$ were similar to those reported in other civilian studies (e.g., Vreven et al., 1995) but lower than typically reported for the military version. The magnitude of PTSD scores varied by traumatic event, with PTSD symptomatology highest for students who reported an event that is too difficult to discuss, a crime, a rape, or child abuse. PTSD symptomatology was lower among those whose worst experiences involved accidents or natural disasters but the timing, type, and severity of exposure to the disaster were not reported. Correlations between the C-Mississippi Scale and other measures of PTSD were lower than those between the C-Mississippi Scale and other more general measures of psychopathology, suggesting that the C-Mississippi Scale may measure more general psychological distress rather than PTSD. Confirmatory factor analysis yielded inconsistent factors across these two studies and between these two studies and those of other researchers (King \& King, 1994; Vreven et al., 1995).

Several authors have called for further study of the Mississippi Scale's performance when administered to community-based civilians (Green, 1991; Vreven 
et al., 1995) or urged caution in utilizing it in civilian samples (Lauterbach et al., 1997; Vreven et al., 1995). The C-Mississippi Scale was included along with several other measures of psychological distress in a community survey (Bourque \& Russell, 1994; Bourque, Russell, \& Goltz, 1993) following the 1989 Loma Prieta earthquake in California, which resulted in 63 deaths, 3757 injuries, and extensive property damage throughout the San Francisco Bay Area (Benuska, 1990). These data provided the opportunity to examine the reliability and dimensionality of the Mississippi Scale in this population-based community sample and to present descriptive statistics for the scale.

Although no other standardized PTSD measures were administered in the Loma Prieta survey, the Brief Symptom Inventory (Derogatis, 1977) and the Traumatic Stress Schedule (Norris, 1990) were available to assess the psychometric properties of the C-Mississippi Scale. The Mississippi Scale was compared to the BSI to assess convergent validity. Because experiences during a natural disaster are thought to be associated with degree of PTSD symptomatology (Green, 1990, 1993; Norris \& Perilla, 1996), scores on the C-Mississippi Scale were compared with earthquake-related experiences including damage to the home, evacuation of the residence, and injury to the respondent or an acquaintance and to characteristics previously associated with PTSD including female gender (Norris, 1992) and lower educational level (Breslau, Davis, Andreski, \& Peterson, 1991). C-Mississippi Scale scores were examined in relation to other non-earthquakerelated traumatic stressors using the Traumatic Stress Schedule (Norris, 1990), as these experiences may contribute to PTSD symptomatology (Kramer \& Green, 1991). Finally, scale dimensionality was examined with factor analysis because recent analyses of the NVVRS data demonstrate lower internal consistency and slightly different factor structures for the C-Mississippi Scale than for the original combat version (Vreven et al., 1995).

This study describes the performance of the Civilian Mississippi Scale in a community sample. This study is unique in that (1) it examines the performance of the C-Mississippi Scale in a population-based civilian sample; (2) the study was anchored to a specific natural disaster, thus permitting dose-response analyses; (3) data were collected by telephone interview rather than through face-to-face administration or supervised self-administration (Bourque \& Fielder, 1995); and (4) it examines a possible methodological artifact in the C-Mississippi Scale that may help to explain some of the diverse findings of other researchers (Lauterbach et al., 1997; Norris \& Perilla, 1996; Vreven et al., 1995).

\section{Method}

\section{Sample}

The sample included 656 adults who resided in the San Francisco Bay Area at the time of the earthquake. Characteristics of the sample are presented in Table 1. 
Table 1. Demographic Characteristics and Traumatic Experiences of Survey Respondents

\begin{tabular}{|c|c|c|}
\hline Categorical Variable & $n$ & $\%$ \\
\hline \multicolumn{3}{|l|}{ Gender } \\
\hline Male & 290 & 44.2 \\
\hline Female & 366 & 55.8 \\
\hline \multicolumn{3}{|l|}{ Ethnicity } \\
\hline White & 495 & 75.5 \\
\hline Nonwhite & 160 & 24.4 \\
\hline \multicolumn{3}{|l|}{ Education } \\
\hline No high school diploma & 64 & 9.8 \\
\hline High school diploma & 144 & 31.7 \\
\hline Education beyond high school & 448 & 68.3 \\
\hline \multicolumn{3}{|l|}{ Employment } \\
\hline Employed & 452 & 68.9 \\
\hline Not employed & 188 & 28.7 \\
\hline Unemployed & 16 & 2.4 \\
\hline \multicolumn{3}{|c|}{ Suffered any damage to residence from quake } \\
\hline Yes & 217 & 33.0 \\
\hline No & 439 & 67.0 \\
\hline \multicolumn{3}{|c|}{ Experienced non-quake-related trauma in past year } \\
\hline Yes & 159 & 24.0 \\
\hline No & 497 & 76.0 \\
\hline \multicolumn{3}{|c|}{ Quake caused injury to self or acquaintance } \\
\hline Yes & 80 & 12.2 \\
\hline No & 576 & 87.8 \\
\hline
\end{tabular}

Note. $N=656$ (unweighted sample). Mean age $=42$ years (range, 18 to 94 years). Mean income $=\$ 45,000$.

Demographic characteristics of survey respondents generally represent the 1990 census population of the region, although there were more female respondents, a higher mean age, and more high school graduates (typical in community surveys) (Aday, 1989).

\section{Instrument}

Mississippi Scale for PTSD (Civilian Version). The Mississippi Scale is a composite index of self-reported PTSD symptomatology, composed of 35 equally weighted items scored on a 5 -point Likert scale. ${ }^{6}$ Ten of the 35 items use reversed

\footnotetext{
${ }^{6}$ Four items were added to the 35 -item civilian version after its application and validation in a control group of civilians for the National Vietnam Veterans Readjustment Study (NVVRS). New items include Item 36 ("At times I suddenly act or feel as though something that happened in the past were happening all over again"), Item 37 ("I am not able to remember some important things that happened in the past"), Item 38 ("I feel 'superalert' or 'on guard' much of the time"), and Item 39 ("If something happens that reminds me of the past, I get so anxious or panicky that my heart pounds hard; I have trouble getting my breath, I sweat, tremble or shake; or feel dizzy, tingly, or faint"). During pretesting for the Loma Prieta study, Item 39 produced laughter from the respondents and subsequently was
} 
wording (e.g., Item 2, "I do not feel guilt for things I did in the past"). These items are recoded for analysis so that a high value for the item reflects PTSD symptomatology. Possible PTSD scores in the Mississippi Scale range from a minimum of 35 to a maximum of 175 . No time frame is specified within which events are expected to have occurred.

A unique characteristic of our study was the inclusion of the C-Mississippi Scale as part of a telephone survey, the use of an implied anchor (Loma Prieta earthquake), and standard response categories. Previous versions of the Mississippi Scale utilized shifting response options, commonly ranging from "never" to "very frequently" and "never true" to "very frequently true." For reasons similar to those suggested by Norris and Perilla (1996), we revised the response options to make them consistent for telephone interviews. Response options for 33 items were replaced to be consistent with two other items; interviewers stated, "I am now going to read you a list of statements that people sometimes use to describe themselves. As I read each one, please tell me whether that statement is "not at all true" of you, "slightly true" of you, "somewhat true" of you, "very true" of you, or "extremely true of you," and continued with the PTSD item list.

Brief Symptom Inventory. The 53-item Brief Symptom Inventory (BSI; Derogatis \& Spencer, 1982), a shortened version of the 90-item Symptom Checklist (SCL-90), measures nine dimensions of psychological distress (Psychoticism, Somatization, Depression, Hostility, Phobic Anxiety, Obsessive-Compulsive, Anxiety, Paranoid Ideation, and Interpersonal Sensitivity subscales) using self-reported ratings of symptomatology (on a 5-point Likert scale). Respondents were asked if symptoms occurred ". . . in the past two weeks, including today." The BSI General Severity Index is scored as a sum of item scores adjusted for the number of items with valid responses. The BSI serves as an index of psychological distress and has been found to be reliable and to have satisfactory psychometric properties (Green, 1991). Cronbach's $\alpha$ in the Loma Prieta study was $.95(n=633)$.

Traumatic Event Scale. To assess the cooccurrence of traumatic experiences that were unrelated to the Loma Prieta earthquake but were potential precursors to PTSD, a series of questions was adapted from the Traumatic Stress Schedule (TSS; Norris, 1990), also used in a survey with the C-Mississippi Scale following Hurricane Andrew (Norris \& Perilla, 1996). The scale was introduced with the statement

The next set of questions ask about experiences, other than the earthquake, that you may have had during the last year. Since (INSERT MONTH, YEAR), have you had any of the following experiences?

replaced in the instrument by a new item ("I feel numb"). Analyses were done with both the 35-item and the 39-item scales with comparable results. In factor analyses, the four new items loaded with the 25 nonreversed items. Cronbach's $\alpha$ for the 39-item scale was .77 and that for the 29-item scale was .86. Analyses of the 35-item scale are presented here for comparability with previous studies of the combat and civilian scales. Analyses of the 39 -item scale are available from the authors. 
Respondents reported whether they had experienced one of six traumatic events (forceful robbery, violent assault, forced sex, auto accident with injury, violent or accidental death of a loved one, traumatic life change) or "some other terrifying or shocking experience" within the year preceding the interview (which for some respondents included a period of up to 6 months before the earthquake). Responses were summed and can range from 0 to 7.

\section{Procedure}

The Loma Prieta Earthquake Study was conducted over a 3-month period, beginning 6 months after the earthquake, which struck October 17, 1989, at 5:04 PM with a magnitude of 6.9 on the Richter scale. A sample of 656 adult residents in San Francisco, Alameda, San Mateo, Santa Clara, and Santa Cruz counties was obtained. Modified random digit dialing (rdd) using a prescreened sample of numbers from Survey Sampling, Inc., was used to obtain a representative sample. Telephone numbers were stratified by Modified Mercalli Intensity (MMI) ${ }^{7}$ to ensure that sufficient residents from high-impact areas were represented in the sample (Bourque, Shoaf, \& Nguyen, 1997). Eligible households were those that were located in the five-county area and that had a working residential telephone. The following statement was read to the person who answered the phone.

Good (morning/afternoon/evening). I'm (...) from the Survey Research Center at UCLA. We are conducting a study to find out about people's recent experiences with earthquakes. Our questions are about both the recent Bay Area earthquake, and about people's experiences in other earthquakes. Findings from the study will be made available to state and local legislators, policy makers, and planners.

Adults in the household who lived in the area on October 17, 1989, were listed and the actual respondent was selected using Kish procedures (1965). Only that one resident of each household was interviewed. Telephone interviews were conducted in either English or Spanish, according to the preference of the respondent; 12 respondents chose to be interviewed in Spanish.

Area households were stratified by Modified Mercalli Intensities (MMI). Two sample strata were selected for over sampling using MMI to ensure adequate representation of geographic areas with high earthquake shaking intensity. These included areas of San Francisco, Alameda, and Santa Cruz counties with isoseismal scores of 8 or above. A total of 83 respondents (13\%) was selected from the highimpact areas of San Francisco and Alameda, 122 (19\%) from the high-impact areas of Santa Clara and Santa Cruz Counties, and 451 (69\%) from households

\footnotetext{
${ }^{7}$ The Modified Mercalli Intensity (MMI) scale is a 12-point scale that is based on perceived ground shaking and observable damage where 1 equals "not felt" and 12 equals "practically all works of construction damaged greatly or destroyed." The highest MMIs reported after the Loma Prieta earthquake were 8 “. . . Considerable [damage] in ordinary substantial buildings ..." and 9 "... Damage considerable in (masonry) structures built especially to withstand earthquakes ..." (Applied Technology Council, 1985).
} 
in the remaining areas of the five Bay Area counties. Thus, the population used for this analysis included 451 households sampled from low-impact areas of the five counties and 205 households sampled from highly affected geographical areas. Twenty-seven respondents were eliminated from these analyses because they failed to answer one or more Mississippi Scale items.

Calculating response rates with procedures recommended by the American Association for Public Opinion Research (1998) and the Council of American Survey Research Organizations (1982), which account for every phone number in the original population of 1640 rdd-selected numbers, response rates for the identified strata ranged from $69 \%$ in the five-county area to $81 \%$ for the Santa Cruz area. Of the 811 households with an eligible, capable respondent who was successfully contacted, $656(80.9 \%)$ completed the interview. Underrepresented groups in the survey included homeless persons, households without telephones, and non-English non-Spanish speakers (Bourque et al., 1993).

Weighted vs. Unweighted Analysis. Since geographical areas with more intensive shaking are overrepresented, the data must be weighted to produce population-based estimates. Analyses from the weighted and unweighted data resulted in similar findings, and thus, analyses presented here utilize the unweighted sample because they are more easily interpreted.

\section{Statistical Analysis}

Cronbach's $\alpha$ and item-total correlations were used to assess scale reliability. Principal axis factor analysis was performed using both varimax and oblique rotation to assess the dimensionality and factor structure of the 35-item scale. Analysis of variance was used to compare groups formed with regard to selected demographic characteristics, experiences following the earthquake, and states of psychological distress. Correlation coefficients were computed to examine associations between Mississippi Scale scores and measures of exposure to nonearthquake-related traumas and psychological distress. Multivariate least-squares regressions were conducted to assess relationships of these variables with the Mississippi Scale and with the scale factors.

\section{Results}

\section{Characteristics of the Interview Experience}

Interview length averaged $34.3 \mathrm{~min}$ and ranged from 16 to $90 \mathrm{~min}$. There is no evidence that respondents became fatigued or bored during the interview. No respondents refused to answer questions about location during the earthquake, whether they had damage, and how prepared they felt. For the 53-item BSI, 17 persons refused one item, 3 persons refused two items, 1 person refused 26 items, 
and 1 person refused 52 items; the latter 2 cases were dropped from analyses that included the BSI.

For the 39-item C-Mississippi Scale, 19 persons refused one item, 3 persons refused two items, 1 person refused three items, and 4 persons refused all 39 items; these cases were dropped from all analyses. At the end of the interview, 80 respondents $(12 \%)$ refused a future interview.

\section{Internal Consistency and Descriptive Analysis}

Cronbach's $\alpha$ was .74 for the 35-item C-Mississippi Scale. Corrected itemtotal correlations ranged from -.03 to .43 , with a mean item-total correlation of .27 (data available from the authors upon request). C-Mississippi Scale scores ranged from 45 to 130 , with a median score of $66(M=67.4, S D=9.9)$.

\section{Scale Validity}

C-Mississippi scores were higher for residents of the two high-impact earthquake areas $[M=69.4, S D=10.4$, for San Francisco/Alameda $(n=84) ; M=$ 69.0, $S D=12.0$, for Santa Clara/Santa Cruz $(n=121)]$ than for respondents residing in the rest of the five-county region $[M=66.5, S D=9.1 ; n=435 ; F(2,626)=$ $7.63, p<.01]$. Mean scale scores were higher among respondents who incurred financial damage $(M=69.5, S D=10.8 ; n=213)$ than for those who had no damage $[M=66.3, S D=9.3, n=416 ; F(1,627)=16.45, p<.001]$. Respondents who evacuated their homes after the quake because of damage or distress had higher C-Mississippi Scale scores $(M=70.3, S D=12.1 ; n=141)$ than respondents who did not leave their homes $[M=66.5, S D=9.1 ; n=488 ; F(1,627)=16.40, p<$ .001]. No differences were found in mean Civilian Mississippi Scale scores between respondents who had been injured or knew someone injured in the quake and respondents who had no experience with injury.

Respondents who reported traumatic personal experiences (unrelated to the earthquake) within the past year had higher C-Mississippi scores $(M=70.9, S D=$ $11.0 ; n=153$ ) than those who reported no traumatic experiences $[M=66.2, S D=$ $9.3 ; n=476 ; F(1,627)=27.10, p<.001]$.

C-Mississippi scores were unexpectedly higher for men $(M=68.2, S D=$ $10.5 ; n=276)$ than for women $[M=66.4, S D=9.5 ; n=353 ; F(1,626)=3.76$, $p=.05]$. Scores were higher for younger people (45 years or less) $(M=69.5$, $S D=10.4 ; n=373)$ than older people $[M=64.2, S D=8.3 ; n=252 ; F(1,627)=$ $46.40, p<.001]$. Currently employed individuals had higher average scale scores $(M=68.6, S D=10.0 ; n=440)$ than unemployed respondents $(M=65.9$, $S D=9.1 ; n=14)$ or those who were retired, homemakers, or students $[M=64.3$, $S D=9.2 ; n=175 ; F(2,626)=12.29, p<.001]$. C-Mississippi scores did not differ with ethnicity or education. 
The study did not include a diagnostic measure of PTSD. However, moderate correlations were found between the C-Mississippi Scale and conceptually related measures: the General Severity Index of the BSI $[r(628)=.49, p<.001]$, the BSI Anxiety subscale $[r(628)=.37, p<.001]$, and the BSI Depression subscale $[r(628)=.40, p<.001]$.

Two-way analysis of variance was used to compare how earthquake experiences and prior personal traumas independently and in combination predicted PTSD. Whether or not a respondent reported traumatic personal experiences (unrelated to the earthquake) within the last year was combined, in turn, with whether or not the respondent reported damage from the earthquake, evacuated because of the earthquake, knew persons who were injured in the earthquake, and lived in a high-impact area. In all analyses but those which included reports of quakerelated injuries, main effects for both the victimization variable and the respective earthquake-related variable were significant, but none of the two-way interaction terms were significant. For example, when reports of quake damage were combined with reports of nonquake victimization to predict the 35-item C-Mississippi scale, the mean PTSD score for those who reported neither damage or victimization was 65.7, while the mean score was 67.1 for those who reported damage but no victimization, 69.1 for those who reported no damage but victimization, and 73.3 for those who reported both damage and victimization $[F(1,625)=25.6, p<.001$, for victimization; $F(1,625)=7.5, p<.01$, for damage; $F(1,625)=2.3$, ns]. Similar patterns were found in all the two-way analyses of variance.

\section{Dimensionality}

Principal-axis factor analysis using varimax procedures produced a simple structure factor solution. Ten factors with eigenvalues greater than 1.00 were extracted in the unrotated factor analysis, but the scree plot suggested a factor solution with two true factors. Factor 1 had an eigenvalue of 6.53 and explained $19 \%$ of the variance; Factor 2 had an eigenvalue of 3.08 and explained $9 \%$ of the variance.

To examine further the characteristics of the two factors, a principal-axis factor analysis restricted to a two-factor solution was performed and rotated using both the varimax and the oblique procedure. Since the two methods produced similar results, varimax-rotated solutions are presented (Table 2).

The first factor with an eigenvalue of 5.79 (16\% of the variance) in the unrotated analysis contained the 25 nonreversed items and the first reversed item (Item 2 ) of the scale (26 items in total). When rotated, the first factor contained the 25 nonreversed wording items and the second factor contained all 10 reversed items. Item 2 was the only item with a factor loading of less than .30 .

Scale Factors. Factor analytic data indicate that the 35 items in the CMississippi Scale did not form a single unidimensional scale in this community sample. 
Table 2. Principal Axis Factoring Analysis Factor Loadings of 35 Mississippi Scale Items Following Varimax Rotation, Restricted to Two Factors, Communalities of Mississippi Scale Items, and Item-Total Correlations of Factors

\begin{tabular}{|c|c|c|c|c|c|}
\hline \multirow[b]{2}{*}{ Item } & \multirow[b]{2}{*}{ Content } & \multicolumn{2}{|c|}{ Factor Loading } & \multirow[b]{2}{*}{ Communality } & \multirow{2}{*}{$\begin{array}{l}\text { Item-Total } \\
\text { Correlation }\end{array}$} \\
\hline & & Factor 1 & Factor 2 & & \\
\hline 23 & Frightened by my urges & .62 & -.01 & .38 & .57 \\
\hline 14 & Dreams at night are so real I wake up & .57 & -.00 & .32 & .51 \\
\hline 04 & Reminds me of the past & .56 & -.11 & .33 & .38 \\
\hline 28 & Can never tell anyone things I've done & .56 & .07 & .32 & .52 \\
\hline 26 & Do not understand & .56 & -.07 & .32 & .53 \\
\hline 33 & Try to stay away from reminders & .56 & -.08 & .31 & .51 \\
\hline 15 & Cannot go on & .55 & -.07 & .31 & .48 \\
\hline 21 & Cry for no good reason & .54 & -.09 & .30 & .51 \\
\hline 07 & Nightmares of things that happened & .52 & .02 & .28 & .48 \\
\hline 13 & Back in the past & .51 & -.01 & .26 & .49 \\
\hline 35 & Hard time expressing feelings & .48 & -.10 & .24 & .45 \\
\hline 20 & Trouble concentrating & .47 & -.12 & .24 & .44 \\
\hline 29 & Use alcohol to make me sleep or forget & .45 & .05 & .21 & .41 \\
\hline 31 & Lose my cool and explode & .45 & -.01 & .20 & .42 \\
\hline 18 & Daydreams are very real & .45 & -.08 & .21 & .40 \\
\hline 09 & Have no feelings & .43 & -.03 & .19 & .42 \\
\hline 08 & When I think of past wish I were dead & .42 & .04 & .18 & .35 \\
\hline 25 & Noises make me jump & .42 & -.02 & .18 & .40 \\
\hline 12 & Why am I still alive when others dead & .42 & .03 & .18 & .39 \\
\hline 16 & Do not laugh or cry & .37 & -.17 & .17 & .36 \\
\hline 03 & Likely to become violent & .37 & -.02 & .14 & .37 \\
\hline 01 & Had more close friends in past & .36 & -.17 & .16 & .35 \\
\hline 10 & I have felt like killing myself & .34 & .01 & .12 & .29 \\
\hline 32 & Afraid to go to sleep & .32 & -.12 & .12 & .30 \\
\hline 05 & People who know me are afraid of me & .31 & -.05 & .10 & .29 \\
\hline 30 & Feel comfortable in crowd & -.12 & .62 & .40 & .50 \\
\hline 34 & Memory is as good as it ever was & -.02 & .57 & .32 & .48 \\
\hline 22 & Enjoy company of others & .02 & .54 & .29 & .44 \\
\hline 24 & Fall asleep easily & -.00 & .53 & .28 & .46 \\
\hline 17 & Still enjoy doing things & -.04 & .52 & .27 & .42 \\
\hline 19 & Found it easy to keep a job & -.08 & .50 & .25 & .42 \\
\hline 27 & I am easy-going even-tempered person & .12 & .43 & .20 & .33 \\
\hline 11 & Fall asleep until alarm goes off & -.08 & .40 & .17 & .38 \\
\hline 06 & Emotionally close to others & -.04 & .38 & .15 & .33 \\
\hline 02 & Do not feel guilt & -.18 & .20 & .07 & .19 \\
\hline
\end{tabular}

Note. Item content has been summarized for brevity.

Item sets for each factor were summed to produce two "subscales" of the C-Mississippi Scale; as in all analyses of the C-Mississippi Scale, the 10 items with reversed wording were recoded so that a high item value indicated PTSD symptomatology. Internal consistency analyses produced Cronbach's $\alpha$ 's of . 86 for the nonreversed item factor (item-total correlations of .29 to .57) and .73 for the reversed-item factor (item-total correlations of .19 to .50) (analyses available from the authors upon request). The correlation between the nonreversed item factor and the reversed item factor was low and negative $[r(628)=-.15, p=.001]$. 
Compared with indices of psychological distress and specific traumatic stress measures, the BSI Global Severity Index (GSI) was more highly correlated with the 25-nonreversed item factor $[r(628)=.76, p<.001]$ than with the 35item scale $[r(628)=.49, p<.001]$. The BSI GSI was negatively correlated with the 10-reversed item factor $[r(628)=-.23, p<.001]$. Correlations of the 25nonreversed item scale were high and positive with the BSI Anxiety Subscale $[r(628)=.62, p<.001]$ and the BSI Depression Scale $[r(628)=.63, p<.001]$, but correlations of the 10-reversed item scale with the BSI Anxiety Scale $[r(628)=$ $-.23, p<.001]$ and the BSI Depression Scale $[r(628)=-.21, p<.001]$ were substantially lower and negative. The 10-reversed item scale was not significantly associated with postearthquake evacuation of the home $[r(628)=-.02, \mathrm{~ns}]$ or with non-quake-related personal traumatic experiences $[r(628)=.00, \mathrm{~ns}]$; modest positive correlations were found between evacuation and non-quake-related traumatic experiences and the 25-nonreversed item scale $[r(628)=.20, p<.001 ; r(628)=$ $.24, p<.001]$ and the 35 -item C-Mississippi scale $[r(628)=.16, p<.001$; $r(628)=.20, p<.001]$.

Staged, multivariate linear regressions examined the relative contribution of characteristics found in previous studies to be associated with PTSD to the 35-item C-Mississippi Scale, the 25-item scale, and the 10-item (recoded) reversed scale. These characteristics included demographic variables (gender, age, ethnicity, education, employment status), earthquake-related trauma (residential impact area, quake-related injury to self or acquaintance, financial damage, residential evacuation), non-earthquake-related trauma, and psychological distress (BSI Anxiety Subscale, BSI Depression Subscale) (see Table 3).

Regressing the 35-item C-Mississippi Scale on the demographic variables resulted in an $R^{2}$ of $.08(p<.001)$. When earthquake and non-earthquake-related trauma variables were added, the change in $R^{2}$ was $.05(p<.001)$, and when psychological distress was added the change in $R^{2}$ was $.14(p<.001)$, resulting in a total $R^{2}$ of $.26(p<.001)$. Statistically significant predictors of high PTSD scores were younger age, male gender, being currently employed, residing in a high-impact area, the BSI Anxiety Subscale, and the BSI Depression Subscale. Reports of residential evacuation and non-quake-related trauma were significant positive predictors of the 35 -item C-Mississippi score until the two BSI subscales were added to the model.

The $R^{2}$ was higher for the 25 -nonreversed item factor $(.50 ; p<.001)$ than for the 35 -item scale $(.26 ; p<.001)$, with a statistically significant difference in the variance explained $[F(12,1182)=45.2, p<.001]$. A lower $R^{2}(.14 ; p<.001)$ was obtained when the 10-reversed item factor was regressed upon demographics $\left(R^{2}\right.$ change $\left.=.07, p<.001\right)$, traumatic experiences $\left(R^{2}\right.$ change $\left.=.02 ; p=.06\right)$, and the BSI subscales $\left(R^{2}=.06, p<.001\right)$. Younger age and male gender were significant predictors of both the 35 -item and the 25 -item scales. Residing in a highimpact area was a significant predictor of the 35 -item scale but not the 25 -item 
Table 3. Multivariate Least-Squares Regression on the 35-Item Civilian Mississippi Scale and the Nonreversed and Reversed Item Factors by Conceptually Related Characteristics

\begin{tabular}{|c|c|c|c|c|c|c|}
\hline \multirow[b]{2}{*}{ Characteristic } & \multicolumn{2}{|c|}{$\begin{array}{l}\text { Mississippi Scale } \\
\quad \text { (35 Items) }\end{array}$} & \multicolumn{2}{|c|}{$\begin{array}{l}\text { Nonreversed } \\
\text { (25 Items) }\end{array}$} & \multicolumn{2}{|c|}{$\begin{array}{l}\text { Reversed } \\
\text { (10 Items) }\end{array}$} \\
\hline & $B$ & SE & $B$ & SE & $B$ & SE \\
\hline \multicolumn{7}{|l|}{ Demographics } \\
\hline $\begin{array}{l}\text { Gender }(0=\text { female } \\
1=\text { male })\end{array}$ & $2.34^{* *}$ & .73 & $1.87^{* *}$ & .50 & .43 & .52 \\
\hline Age $(y r)$ & $-.07^{* *}$ & .02 & $-.04^{*}$ & .02 & -.02 & .02 \\
\hline $\begin{array}{l}\text { Ethnicity }(0=\text { nonwhite, } \\
1=\text { white })\end{array}$ & 1.20 & .86 & -.22 & .59 & $1.37^{*}$ & .62 \\
\hline Education (yrs) & .07 & .12 & -.15 & .09 & $.20^{*}$ & .09 \\
\hline $\begin{array}{l}\text { Employed }(0=\text { not } \\
\quad \text { currently employed, } \\
1=\text { employed })\end{array}$ & $2.04^{*}$ & .95 & -.12 & .64 & $2.36^{* *}$ & .68 \\
\hline$R^{2}$ change & \multicolumn{2}{|c|}{$\begin{array}{c}.08 \\
F(5,592)=9.6^{* * *}\end{array}$} & \multicolumn{2}{|c|}{$F(5,602)=5.7^{* * *}$} & \multicolumn{2}{|c|}{$\begin{array}{c}.07 \\
F(5,603)=9.5^{* * *}\end{array}$} \\
\hline \multicolumn{7}{|l|}{ Traumatic experiences } \\
\hline $\begin{array}{c}\text { Residence in high-impact } \\
\text { area }(0=\text { no, } 1=\text { yes })\end{array}$ & $2.18^{* *}$ & .78 & .44 & .54 & $1.76^{* *}$ & .56 \\
\hline $\begin{array}{l}\text { Quake injury to self or } \\
\text { acquaintance }(0=\text { no, } \\
1=\text { yes })\end{array}$ & -.12 & 1.12 & -.50 & .78 & .19 & .81 \\
\hline $\begin{array}{l}\text { Damage to residence } \\
\text { (total dollars) }\end{array}$ & .00 & .00 & .00 & .00 & .00 & .00 \\
\hline $\begin{array}{l}\text { Evacuation of residence } \\
\quad(0=\text { no, } 1=\text { yes })\end{array}$ & .71 & .90 & $1.29^{*}$ & .62 & -.54 & .65 \\
\hline $\begin{array}{l}\text { Non-quake-related trauma } \\
\quad(0=\text { no, } 1=\text { yes })\end{array}$ & 1.05 & .86 & .47 & .59 & .59 & .62 \\
\hline$R^{2}$ change & \multicolumn{2}{|c|}{$\begin{array}{c}.05 \\
F(5,592)=7.0^{* * *}\end{array}$} & \multicolumn{2}{|c|}{$\begin{array}{c}.08 \\
F(5,602)=10.6^{* * *}\end{array}$} & \multicolumn{2}{|c|}{$F(5,603)=2.2$} \\
\hline \multicolumn{7}{|l|}{ Psychological distress } \\
\hline $\begin{array}{l}\text { Anxiety (BSI Subscale) } \\
\text { Depression (BSI Subscale) }\end{array}$ & $\begin{array}{l}4.20^{* *} \\
5.57^{* *}\end{array}$ & $\begin{array}{r}.98 \\
1.17\end{array}$ & $\begin{array}{l}6.28^{* *} \\
7.54^{* *}\end{array}$ & $\begin{array}{l}.68 \\
.81\end{array}$ & $\begin{array}{l}-2.05^{* *} \\
-2.05^{* *}\end{array}$ & $\begin{array}{l}.70 \\
.83\end{array}$ \\
\hline$R^{2}$ change & \multicolumn{2}{|c|}{$\begin{array}{c}.14 \\
F(2,595)=54.0^{* * *}\end{array}$} & \multicolumn{2}{|c|}{$\begin{array}{c}.38 \\
F(2,605)=228.9^{* * *}\end{array}$} & \multicolumn{2}{|c|}{$\begin{array}{c}.06 \\
F(2,606)=19.3^{* * *}\end{array}$} \\
\hline$R^{2}$ & \multicolumn{2}{|c|}{$\begin{array}{c}.26 \\
F(12,585)=17.5^{* * *}\end{array}$} & \multicolumn{2}{|c|}{$\begin{array}{c}.50 \\
F(12,595)=50.5^{* * *}\end{array}$} & \multicolumn{2}{|c|}{$\begin{array}{c}.14 \\
F(12,596)=8.4^{* * *}\end{array}$} \\
\hline
\end{tabular}

Note. The Mississippi Scale is computed from all 35 items, the nonreversed factor is computed from the 25 items with normal wording, and the reversed item factor is computed from the 10 items with reversed wording (Items 2, 6, 11, 17, 19, 22, 24, 27, 30, and 34). Reversed items are recoded so that high Likert values indicate PTSD symptomatology.

$$
\begin{array}{rl}
{ }^{*} p & <.05 . \\
* * & <<.01 . \\
* * * & p<.001 .
\end{array}
$$


scale, while residential evacuation was a significant predictor of the 25 -item scale but not the 35-item scale.

Regression coefficients for the 10-reversed item scale were significant for white ethnicity, higher educational level, current employment, and residence in a high-impact area. In contrast to the 35-item and 25-item scales, the BSI subscales of Depression and Anxiety were significant negative predictors of scores on the 10 reversed items when controlling for other demographic and traumatic experience variables. In other words, respondents who had little or no evidence of anxiety and depression as measured with the BSI had high PTSD scores when PTSD was measured using the 10 reversed items.

\section{Discussion}

The C-Mississippi Scale did not achieve the levels of internal consistency or item-total correlations reported by Vreven et al. (1995) for the C-Mississippi Scale administered to civilians in the NVVRS or those obtained in previous validation studies of the combat Mississippi Scale. Several issues regarding the performance of the scale are raised by this study's findings.

Factor analysis produced a dominant factor that is consistent with earlier studies of C-Mississippi Scale unidimensionality (King \& King, 1994) and supports the findings by McFall et al. (1990) of a predominant, unidimensional scale. Items with high loadings on the dominant factor include symptoms from each of the three symptom groups required for clinical diagnosis of PTSD (reexperiencing past events, numbing avoidance, and physiological arousal), items from the six factors isolated by Keane et al. (1988) during preliminary validation, and items from the three factor content areas discussed by McFall et al. (1990).

C-Mississippi Scale scores were correlated with (1) psychometric measures that overlap with the PTSD construct, (2) demographic and earthquake-related experiences identified in previous studies as correlates of PTSD, and (3) exposures to non-quake-related personal traumatic experiences that occurred around the time of the earthquake. When controlling for other variables, however, C-Mississippi Scale scores were strongly predicted by non-quake-related traumatic experiences but not by quake-related injury or extent of residential damage. Some have suggested that traumatic events such as natural disasters cause time-limited acute stress disorder [ASD; American Psychiatric Association (APA), 1994] but that many fewer people go on to develop PTSD in response to these events (Koopman, Classen, Cardena, \& Spiegel, 1995). Others have suggested that traumatic personal experiences (such as sexual or physical assault) that result in psychological distress and that are unrelated to the disaster event are a major cause of PTSD detected among residents following a natural disaster (Green, 1991). Our findings suggest that a natural disaster of the magnitude of the Loma Prieta earthquake results in ASD that does not progress to PTSD, while non-disaster-related 
traumatic personal experiences result in the kinds of chronic stress associated with PTSD.

A second, unexpected finding in this study was that men had higher CMississippi Scale scores but lower BSI scores than women. These patterns held even when controlling for other demographic and trauma-related factors. Because the C-Mississippi Scale was originally developed for and validated on Vietnam veterans, one question raised by these findings is whether C-Mississippi Scale items validated primarily on male combat veterans appropriately detect PTSD in community samples and in specific subpopulations within communities (e.g., women) (Bourque \& Russell, 1994; Wolfe, Brown, Furey, \& Levin, 1993).

\section{Methodological Artifact?}

This study identified a possible methodological artifact in the C-Mississippi Scale. A dominant factor was composed of the 25 nonreversed items (those items in which greater respondent agreement indicates greater PTSD), while a second factor included all of the 10 items with reversed wording (those items in which lower respondent agreement with the statement indicates greater PTSD). Higher internal consistency was obtained when the 10 reversed items were removed from the scale, and the low, negative correlation between the two factors provides additional evidence that the 10 reversed items may not contribute to the measure of PTSD. If the 35-item Mississippi Scale, the 25 nonreversed items, and the 10 reversed items all measure PTSD, the item groups theoretically should be related to PTSD correlates found in previous research (e.g., disaster). In fact, such correlates were not consistently predictive of PTSD scores for the two, factor-defined scales.

One explanation is that if the Mississippi Scale identifies symptoms that represent the broad PTSD construct, different item sets may be complementary and correlate with different psychological variables (Vreven et al., 1995; F. Weathers, personal communication, 1993). Item response analyses by King et al. (1994) demonstrate that specific Mississippi Scale items provide varying degrees of information on specific dimensions of PTSD. However, previous studies offer no theoretical explanation for the lack of correlation between factors composed of items worded in different directions. Correlates of high scores on the 10-item scale were generally counterintuitive and inconsistent with previous studies of PTSD. For example, demographic correlates of the reversed item set include white ethnicity, higher education, and current employment.

In our opinion, the second factor is most likely a methodological artifact that results from the directional question wording of 10 of the 35 items. While this artifact has not been identified or explained in the literature, a review of other research on both the combat and the civilian versions of the Mississippi Scale suggests that the reversed items frequently have been identified as weak items in 
the scale. The McFall et al. (1990) analysis of the combat version of the scale used in the NVVRS study produced low factor loadings (i.e., less than .50) for nine M-PTSD items, and seven of the nine items had reversed wording. Keane et al. (1988) eliminated 11 items from the combat version that did not load on any of the six factors at .50 or above; unfortunately, we do not know whether these 11 items included items with reversed wording.

Recent studies suggest that certain reversed items of the C-Mississippi Scale contribute little to the overall PTSD measure (King et al., 1993; Vreven et al., 1995). Seven of the 10 reversed items were among the 10 items reported by Vreven et al. (1995) to have the lowest item-sum correlations. A range of .10 to .53 and a mean of .39 in item-sum scores were reported for the 35 -item scale, and the range in item-sum scores for the 10 reversed items was .10 to .48 with a mean of .30 (Vreven et al., 1995, Table 1, p. 99).

Norris and Perilla (1996, p. 292) created a reduced C-Mississippi Scale by dropping four of the reversed items, with three of the six remaining reversed items in the scale being among the group of nine items that "... did not conform to [the] general pattern. ..." McFall et al. (1990) obtained low item-total correlations for four items (all reversed), while Keane et al. (1987) reported item-total correlations that were generally lower for reversed items than for nonreversed items. For the Civilian Mississippi Scale administered in the NVVRS, Items 2 and 11 displayed low factor loadings across all factors produced (King \& King, 1994), as they did in our analysis. An item-response analysis by King et al. (1994) subsequently demonstrated that several reversed items (Items 2, 6, and 11) contribute little to the overall PTSD measure. Lauterbach et al. (1997) found that Item 2, the first reversed item, had the lowest item-sum correlation in both of the studies they reported.

King and King (1994) speculate that the reversed wording of Item 2 may be confusing to respondents. Item 2 ("I do not feel guilt over the past") is the first reversed item in the scale and may have been understood by fewer respondents than the subsequent nine reversed items, given its position in the scale. This item may have been answered "incorrectly," that is, in a pattern inconsistent with responses for all other items in the scale.

\section{Variations in Administration}

The extent to which the apparent methodological artifact is attributable to the telephone interview format is difficult to assess. Certainly the possibility that respondents "mishear" and fail to understand the reversed responses is increased in a telephone interview. To our knowledge, previous researchers either had respondents fill out the Mississippi Scale questionnaire or administered the scale as part of a face-to-face interview in a clinical setting or a household interview. 
The increased use of telephone interviews in population-based surveys requires reassessment of previously validated instruments (Bourque \& Clark, 1992), and our analysis indicates a need for further validation and assessment of the C-Mississippi Scale as administered, particularly by telephone, in community samples.

While the military version has a stronger validational record than the civilian version, the variations in how the civilian version has been administered makes it more difficult to summarize and interpret psychometric results across studies. The C-Mississippi Scale was originally used (Vreven et al., 1995) with a general reference to the past and no anchor to specific events. Lauterbach et al. (1997) established an implied anchor to the most traumatic event reported by undergraduates, while Norris and Perilla (1996) modified the C-Mississippi Scale by eliminating items and by anchoring items to a specific event. As in this study, Norris and Perilla administered the C-Mississippi Scale using standard response options, a Spanish translation, and an implied anchor (a recent hurricane). Further studies that compare the nonreversed with the reversed items, that contrast the original answer categories with the revised response options used in the Loma Prieta survey and by Norris and Perilla (1996), and that compare the self-administered versions with the telephone and face-to-face administrations are all needed. Administration of the scale in future studies should test the replicability of a possible methodological artifact detected in this study and alluded to in studies by others.

As discussed by Vreven et al. (1995, p. 4), the C-Mississippi Scale may be adequate for obtaining population distributions but inadequate for clinical researchers who need a method for screening for PTSD in civilian populations. This study's findings are consistent with those of Lauterbach et al. (1997) and Norris and Perilla (1996), who find the C-Mississippi Scale more sensitive to personal traumas unrelated to natural disasters than to natural disaster experiences. Unfortunately, the Traumatic Event Scale (Norris, 1990) asks respondents only about traumas they experienced within the last year. Thus, this study does not allow us to assess how lifetime exposures to trauma might affect PTSD as measured by the C-Mississippi Scale.

The finding that a generalized measure of psychological distress (the BSI) was as responsive as the C-Mississippi Scale to both earthquake-induced and nonquake-induced traumas suggests that the C-Mississippi Scale may be more appropriately considered a generalized measure of psychological distress than a measure of posttraumatic stress disorder. In a combined prospective and retrospective study of the 1985 floods in Puerto Rico using the Diagnostic Interview Survey/Disaster Supplement, Canino, Bravo, Rubio-Stipec, and Woodbury (1990) found that depressive and somatic symptoms were as responsive as PTSD symptoms to aspects of the floods. They conclude by suggesting that depressive and somatic symptoms, rather than PTSD, may be the true outcomes of disasters. Similarly Norris and Uhl found that anxiety, depression and somatization as measured with the BSI were elevated in response to both acute and chronic stressors associated with Hurricane Hugo. 
Alternatively, other measures of PTSD may be more responsive to the kinds of acute and chronic stressors that are represented during and immediately after an earthquake or other natural disaster. In recommending the use of standardized psychological measures to assess postdisaster distress, Baum, Solomon, and Ursano (1987) listed a number of scales that might appropriately be considered including the Minnesota Multiphasic Personality Inventory (Lyons \& Wheeler-Cox, 1999), the Impact of Event Scale (Horowitz, Wilner, \& Alvarez, 1979), the Beck (1967) Depression Inventory, the Zung (1965) Depression Scale, the Symptom Checklist 90 (Derogatis, 1977), and the Diagnostic Interview Schedule with or without the Disaster Supplement (Robins et al., 1986; Smith, Robins, Przybeck, Goldring, \& Solomon, 1986). In addition, Norris and Ulm (1993) used the Brief Symptom Inventory following Hurricane Hugo (Derogatis \& Spencer, 1982). All of these measures have been used to measure both aspects of PTSD and other forms of psychological distress following disasters with mixed results. Unfortunately, most studies have administered these measures either in face-to-face interviews or in mailed questionnaires, rather than by telephone. Thus, definitive conclusions regarding which measure provides the most valid data following an earthquake or other natural disaster cannot be determined at this point in time. The National Women's Study PTSD Module, which was adapted from the original DIS and the DIS as modified for the National Vietnam Veterans Readjustment Study (Kulka et al., 1991) and which was developed for telephone administration, might be a likely candidate for future use after disasters, but to our knowledge, it has not yet been used for that purpose.

\section{Acknowledgments}

This study was supported in part by National Science Foundation Grant BCS-9002754. The authors acknowledge the assistance of Todd McNairy and thank Lisa Russell, Ph.D., Drs. Lynda and Daniel King, Judith Siegel, Ph.D., and three anonymous reviewers for helpful reviews of earlier versions of this paper.

\section{References}

Aday, L. (1989). Designing and conducting health surveys: A comprehensive guide. San Francisco: Jossey-Bass.

American Association for Public Opinion Research (1998). Standard definitions: Final dispositions of case codes and outcome rates for RDD telephone surveys and in-person household surveys, May.

American Psychiatric Association (1994). Diagnostic and statistical manual of mental disorders (4th ed.). Washington, DC: Author.

Applied Technology Council (1985). ATC-13 earthquake damage evaluation data for california (Technical Report). Redwood, CA: Author. 
Baum, A., Gatchel, R. J., \& Schaeffer, M. A. (1983). Emotional, behavioral, and physiological effects of chronic stress at Three Mile Island. Journal of Consulting and Clinical Psychology, 51, 565-572.

Beck, A. T. (1967). Depression: Clinical, experimental and theoretical aspects. New York: Hoeber.

Benuska, L. (1990). Loma Prieta earthquake reconnaissance report. Earthquake Spectra, 6, Supplement.

Bourque, L. B., \& Clark, V. A. (1992). Processing data: The survey example. Sage University paper series on Quantitative Applications in the Social Sciences, 07-085. Newbury Park, CA: Sage.

Bourque, L. B., \& Fielder, E. (1995). How to conduct self-administered and mail surveys. The survey kit. Newbury Park, CA: Sage.

Bourque, L. B., \& Russell, L. A. (1994). Experiences during and responses to the Loma Prieta earthquake. Governor's Office of Emergency Services, State of California.

Bourque, L. B., Russell, L. A., \& Goltz, J. D. (1993). Human behavior during and immediately after the earthquake. In The Loma Prieta, California earthquake of October 17, 1989-Public response (U.S. Geological Survey Professional Paper 1553-B, pp. B1-B22). Washington, DC: U.S. Government Printing Office.

Bourque, L. B., Shoaf, K. I., \& Nguyen, L. H. (1997). Survey Research. International Journal of Mass Emergencies and Disasters, 15, 71-101.

Breslau, N., Davis, G. C., Andreski, P., \& Peterson, E. (1991). Traumatic events and posttraumatic stress disorder in an urban population of young adults. Archives of General Psychiatry, 48, $216-222$.

Canino, G., Bravo, M., Rubio-Stipec, M., \& Woodbury, M. (1990). The impact of disaster on mental health: Prospective and retrospective analyses. International Journal of Mental Health, 19, 51-69.

Council of American Survey Research Organizations (CASRO) (1982). On the definition of response rates: A special report of the CASRO Task Force on Completion Rates, Lester R. Frankel, Chairman, Council of American Survey Research Organizations.

Derogatis, L. R. (1977). SCL-90-R: Administration, scoring, and procedures manual. Baltimore: Clinical Psychometrics Research.

Derogatis, L. R., \& Spencer, P. M. (1982). The Brief Symptom Inventory (BSI): Administration, scoring and procedures manual-1. Baltimore, MD: Author.

Green, B. L. (1990). Defining trauma: Terminology and generic stressor dimensions. Journal of Applied Social Psychology, 20, 1632-1642.

Green, B. L. (1991). Evaluating the effects of disasters. Psychological Assessment: A Journal of Consulting and Clinical Psychology, 3, 538-546.

Green, B. L. (1993). Identifying survivors at risk: Trauma and stressors across events. In Wilson, J. P., \& Raphael, B. (Eds.), International handbook of traumatic stress syndromes. New York: Plenum.

Horowitz, M. J., Wilner, N., \& Alvarez, W. (1979). Impact of Events Scale. A measure of psychosomatic stress. Psychosomatic Medicine, 41, 209-218.

Keane, T. M., Wolfe, J., \& Taylor, K. L. (1987). Posttraumatic stress disorder: Evidence for diagnostic validity and methods of psychological assessment. Journal of Clinical Psychology, 43, 32-43.

Keane, T. M., Caddell, J. M., \& Taylor, K. L. (1988). Mississippi Scale for Combat-Related Posttraumatic Stress Disorder: Three studies in reliability and validity. Journal of Consulting and Clinical Psychology, 56, 85-90.

King, D. W., King, L. A., Fairbank, J. A., Schlenger, W. E., \& Surface, C. R. (1994). Enhancing the precision of the Mississippi Scale for Combat-Related Posttraumatic Stress Disorder: An application of item response theory. Psychological Assessment: A Journal of Consulting and Clinical Psychology, 5, 457-471.

King, L. A., \& King, D. W. (1994). Latent structure of the Mississippi Scale for Combat-Related Posttraumatic Stress. Assessment, 1, 275-291.

Kish, L. (1965). Survey sampling. New York: John Wiley.

Koopman, C., Classen, C., Cardena, E., \& Spiegel, D. (1995). When disaster strikes, acute stress disorder may follow. Journal of Traumatic Stress, 8, 29-48.

Kramer, T. L., \& Green, B. L. (1991). Posttraumatic stress disorder as an early response to sexual assault. Journal of Interpersonal Violence, 6, 160-173.

Kulka, R. A., Schlenger, W. E., Fairbank, J. A., Hough, R. L., Jordan, B. K., Marmar, C. R., \& Weiss, D. S. (1990). Trauma and the Vietnam war generation: Report on the findings from the National Vietnam Veterans Readjustment Study. New York: Brunner/Mazel.

Kulka, R. A., Schlenger, W. E., Fairbank, J. A., Hough, R. L., Jordan, B. K., Marmar, C. R., \& Weiss, D. S. (1991). Assessment of posttraumatic stress disorder in the community: Prospects and pitfalls 
from recent studies of Vietnam veterans. Psychological Assessment: A Journal of Consulting and Clinical Psychology, 3, 547-560.

Lauterbach, D., Vrana, S., King, D. W., \& King, L. A. (1997). Psychometric properties of the Civilian Version of the Mississippi PTSD scale. Journal of Traumatic Stress, 10, 499-513.

Lyons, J. A., \& Wheeler-Cox, T. (1999). MMPI, MMPI-2 and PTSD: Overview of scores, scales and profiles. Journal of Traumatic Stress, 12, 175-183.

McFall, M. E., Smith, D. S., Mackay, P. W., \& Tarver, D. J. (1990). Reliability and validity of the Mississippi Scale for Combat-Related Posttraumatic Stress Disorder. Psychological Assessment: A Journal of Consulting and Clinical Psychology, 2, 114-121.

Norris, F. H. (1990). Screening for traumatic stress: A scale for use in the general population. Special Issue: Traumatic stress: New perspectives in theory, measurement, and research. Journal of Applied Social Psychology, 20, Pt. 2, 1704-1718.

Norris, F. (1992). Epidemiology of trauma: Frequency and impact of different potentially traumatic events on different demographic groups. Journal of Consulting Clinical Psychology, 60, 409-418.

Norris, F. H., \& Kaniasty, K. (1992). Reliability of delayed self-reports in disaster research. Journal of Traumatic Stress, 5(4), 575-588.

Norris, F. H., \& Perilla, J. L. (1996). The Revised Civilian Mississippi Scale for PTSD: Reliability, validity, and cross-language stability. Journal of Traumatic Stress, 9, 285-298.

Norris, F. H., \& Uhl, G. A. (1993). Chronic stress as a mediator of acute stress: The case of Hurricane Hugo. Journal of Applied Social Psychology, 23, 1263-1284.

Robins, L. N., Fischback, R. L., Smith, E. M., Cottler, L. B., Solomon, S. D., \& Goldring, E. (1986). Impact of disaster on previously assessed mental health. In Shore, J. (Ed.), Disaster stress studies: New methods and findings. Washington, DC: American Psychiatric Press.

Smith, E. M., Robins, L. N., Przybeck, T. R., Goldring, E., \& Solomon, S. D. (1986). Psychosocial consequences of a disaster. In Shore, J. (Ed.), Disaster stress studies: New methods and findings. Washington, DC: American Psychiatric Press.

Vreven, D. L., Gudanowski, D. M., King, L. A., \& King, D. W. (1995). The Civilian Version of the Mississippi Scale: A psychometric evaluation. Journal of Traumatic Stress, 8, 91-109.

Wolfe, J., Brown, P. J., Furey, J., \& Levin, K. B. (1993). Development of a wartime stressor scale for women. Psychological Assessment, 5(3), 330-335.

Zung, W. W. K. (1965). A self-rating depression scale. Archives of General Psychiatry, 12, 63-70. 